\title{
Taurine improves the spatial learning and memory ability impaired by sub-chronic manganese exposure
}

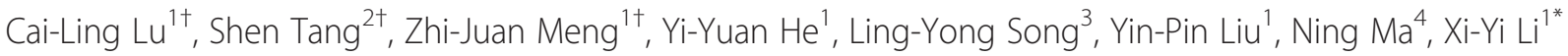 \\ and Song-Chao Guo ${ }^{1 *}$
}

\begin{abstract}
Background: Excessive manganese exposure induced cognitive deficit. Several lines of evidence have demonstrated that taurine improves cognitive impairment induced by numerous neurotoxins. However, the role of taurine on manganese-induced damages in learning and memory is still elusive. This goal of this study was to investigate the beneficial effect of taurine on learning and memory capacity impairment by manganese exposure in an animal model.

Results: The escape latency in the Morris Water Maze test was significantly longer in the rats injected with manganese than that in the rats received both taurine and manganese. Similarly, the probe trial showed that the annulus crossings were significantly greater in the taurine plus manganese treated rats than those in the manganese-treated rats. However, the blood level of manganese was not altered by the taurine treatment. Interestingly, the exposure of manganese led to a significant increase in the acetylcholinesterase activity and an evidently decrease in the choline acetyltransferase activity, which were partially restored by the addition of taurine. Additionally, we identified 9 differentially expressed proteins between the rat hippocampus treated by manganese and the control or the manganese plus taurine in the proteomic analysis using the 2-dimensional gel electrophoresis followed by the tandem mass spectrometry (MS/MS). Most of these proteins play a role in energy metabolism, oxidative stress, inflammation, and neuron synapse.
\end{abstract}

Conclusions: In summary, taurine restores the activity of AChE and ChAT, which are critical for the regulation of acetylcholine. We have identified seven differentially expressed proteins specifically induced by manganese and two proteins induced by taurine from the rat hippocampus. Our results support that taurine improves the impaired learning and memory ability caused by excessive exposure of manganese.

\section{Background}

Manganese $(\mathrm{Mn})$ is an essential nutrient involved in the regulation of multiple metabolic pathways. However, $\mathrm{Mn}$ can be toxic to many organs at a high concentration. The brain is particularly susceptible to the Mn toxicity. Excessive occupational or environmental Mn exposure is associated with multiple neurotoxic effects. Early neuropsychologic symptoms such as deficits in memory,

\footnotetext{
*Correspondence: Ixy_0726@163.com; 2433164518@qq.com

${ }^{\dagger}$ Equal contributors

'Department of Food and Nutrition, School of Public Health, Guangxi Medical University, 22 Shuangyong Road, 530021 Nanning, Guangxi, P.R. China

Full list of author information is available at the end of the article
}

concentration, and spatial orientation are also observed in patients with Mn poisoning [1-3]. Unfortunately, the available treatment option for $\mathrm{Mn}$ poisoning is still very limited. L-3,4-dihydroxyphenylalanine (L-dopa) has been demonstrated possessing some therapeutic effects against Mn-poisoning but it fails to improve the parkinsonismlike symptoms such as walk time, tapping hand in manganese exposure welders [4]. Chelation agents like EDTA or para-aminosalicylic acid (PAS) have also been used to treat Mn poisoning. However, past studies have reported some conflicting results of EDTA about its therapeutic effects on manganism $[5,6]$. Therefore, it is very important to develop an effective therapy to prevent permanent neurological damages mediated by manganese at early stage. 
Taurine is one of the free sulphur-containing amino acids that is widely distributed in human body, including blood plasma, heart, muscle, and brain tissue. Previous studies have reported that taurine has a neuroprotective effect against L-glutamate-induced excitotoxicity [7]. Taurine supplementation has been shown to benefit neuronal proliferation and synaptogenesis, suggesting its effects on enhancing synaptic plasticity and improving learning and memory [8]. Taurine has also been reported to improve the symptoms of metal-induced intoxication for lead and cadmium [9-11]. No severe side effects have been associated with taurine treatment. However, the effects of taurine on the learning and memory impairment induced by manganese exposure is still unknown.

In this study, we aimed to examine the role of taurine against $\mathrm{Mn}$ poisoning with a focus on the spatial learning and memory function in a rat model. We also explored the molecular mechanism of taurine in alleviating the $\mathrm{Mn}$ induced neurological symptoms by evaluating acetylcholine synthesis and degradation. In addition, we conducted a systematic proteomic analysis by mass spectrometry to gain an insight into the genome-wide taurine-specific change in the protein expression profile. Our results provided novel evidences to support that taurine has a protective role in the Mn-induced neurotoxicity.

\section{Methods}

\section{Animal study}

60 male Sprague-Dawley rats weight $(120 \pm 10) \mathrm{g}$ (approximately 6 weeks of age) were obtained from the experimental animal center of Guangxi Medical University (License No:SCXKGui2009-0002). All rats were supplied local tap water ad libitum, which contained the level of $\mathrm{Mn}$ that was below the detection limit. Rats were randomly assigned into 3 groups (20 rats/group): control, $\mathrm{Mn}$, and taurine plus Mn group. $\mathrm{Mn}$-administrated rats were injected intraperitoneally by $15 \mathrm{mg} / \mathrm{kg} \mathrm{MnCl}_{2} \cdot 4 \mathrm{H}_{2} \mathrm{O}$ daily for 8 weeks. The rats in the taurine plus $\mathrm{Mn}$ group were injected intraperitoneally for $15 \mathrm{mg} \mathrm{MnCl}_{2} \cdot 4 \mathrm{H}_{2} \mathrm{O} / \mathrm{kg}$ and $200 \mathrm{mg}$ taurine $/ \mathrm{kg}$ daily for 8 weeks. All rats were weighed daily to calculate the dosage of manganese and taurine treatment. Control animals received daily physiological saline injection for 8 weeks. All solutions were prepared with Milli- $Q^{\text {tw }}$ water. The procedures of animal experiments were in accordance with the protocols approved by the ethical committee for animal experiment of the Guangxi Medical University (GXMU-2014-036).

\section{Morris water maze}

The Morris Water Maze was carried out within $24 \mathrm{~h}$ after last injection and was used to assess animal learning and memory ability [12]. The water maze used in our study was a flat black galvanized metal tank that was
$210 \mathrm{~cm}$ in diameter and equipped with a platform $1-2 \mathrm{~cm}$ below the surface of the water. A camera was mounted above the maze and connected to a computer equipped with the Morris Water Maze analysis software (Huaibei Zhenghua biological equipment Co. China) to record the swimming track in the water maze. Before the learning trail, animals were placed on the fixed platform for $10 \mathrm{~s}$ to familiarize themselves with the task. The animals facing to the pool wall were then trained to find the fixed platform from different locations (N, S, E, W) around the edge of the pool every day for 7 days. The trial was terminated once the animals reach the platform. If the animals failed to locate the platform within 90s, the animal was placed on the platform and the latency was recorded as $90 \mathrm{~s}$. The time $(\mathrm{s})$, swimming distance $(\mathrm{cm})$, and speed $(\mathrm{cm} / \mathrm{s})$ of escape latency to find the platform was used to evaluate the animal spatial memory. A surroundings and visual objects were positioned at fixed locations to serve as cues for the platform location. On day 8, a spatial probe trial was conducted with the original platform removed. The cumulative times spending in the original platform location was recorded during a period of $90 \mathrm{~s}$.

\section{Blood manganese level measurement}

$24 \mathrm{~h}$ after Morris Water Maze test, the animals were euthanized with pentobarbital $(10 \mathrm{mg} / \mathrm{kg})$. The blood of heart were immediately collected in polystyrene tubes which were previously washed by $10 \% \mathrm{HNO} 3$ (Ultrapure grade, sigma, America) for $24 \mathrm{~h}$ and stored at $-80^{\circ} \mathrm{C}$ until $\mathrm{Mn}$ analyses were conducted. $1 \mathrm{ml}$ blood were digested with $3 \mathrm{ml} \mathrm{HNO} 3(65 \%)$ for $24 \mathrm{~h}$ at $130^{\circ} \mathrm{C}$. The Inductively Coupled Plasma Atomic Emission Spectroscopy (ICPAES) was used to analyze the level of manganese.

\section{Determination of acetylcholinesterase (AChE) and choline acetyltransferase (ChAT) activity}

The measurement of AChE activity was based on the reaction of thiocholine, resulting from the enzymatic hydrolysis of acylthiocholines with 5, 5' dithiobis-2-nitrobenzoic acid (DTNB). The reaction solution was read at $412 \mathrm{~nm}$ and the enzyme activity was calculated in unit per gram of input protein. The activity of ChAT was determined by the ACh synthesis reaction that ChAT catalyzed (AcetylCoA + choline - > Acetylcholine + Co-enzyme A). The experiment were performed according to the instruction of the ChAT activity kit (Nanjing Jiancheng Bioengineering Institute, China). The wavelength of spectrometer reading was at $324 \mathrm{~nm}$. The activity of ChAT was expressed in unit per wet weight of hippocampus.

\section{Protein sample preparation for rat hippocampus}

Hippocampus of rats in the control, Mn and taurine plus $\mathrm{Mn}$ groups were dissected and lysed by the protein extraction buffer containing $20 \mathrm{mM}$ Tris, $7 \mathrm{M}$ urea, $2 \mathrm{M}$ 
thiourea, 4\% CHAPS, $10 \mathrm{mM}$ 1,4-dithioerythritol, 0.5\% ampholyte (4-7) and one tablet of protease inhibitors (Roche Diagnostics). Hippocampus were homogenized and centrifuged at $50000 \times g$ for $120 \mathrm{~min}$. The supernatant were collected and the protein concentration in the supernatant was determined by the Bradford method (BioRad).

\section{Two-dimensional gel electrophoresis}

Isoelectric focusing was carried out by using the ETTAN IPGPhor apparatus (GE Healthcare) in Immobiline Dry Strip holders followed by approximately $750 \mu \mathrm{g}$ protein loaded in ready strip. Briefly, a $24 \mathrm{~cm} \mathrm{pH}$ 4-7 strip (GE Healthcare) was hydrated, focused, then equilibraten twice in equilibration buffer for 15 min. The IEF strips were placed on top of the $12.5 \%$ homogeneous polyacrylamide gels $(26 \mathrm{~cm}-\mathrm{w} 20 \mathrm{~cm}-\mathrm{h}$ $1.0 \mathrm{~mm}$-thick) in an Ettan DALT12 (GE Healthcare) gel apparatus. After the second-dimensional separation finish, the SDS-polyacrylamide gels were fixed and stained with silver nitrate. Gels were scanned on ProXpress CCD scanner (Perkin-Elmer). The images were then captured and analyzed by the Image Master 2D platinum 5.0 software, including background adjustment, landmark annotation, protein spot matching and points of difference analysis. At least three independent experiments were conducted for each group.

\section{Protein identification and analysis}

The candidate protein spots were resected and dehydrated. The supernatant of rehydrated samples were then collected and analyzed in a time-of-flight mass spectrometer (Voyager DE-Pro Applied Biosystem). Peptide matching and protein searches were performed in the Swiss-prot database using MASCOT software. The analysis of the biological functions of identified proteins was based on the protein databases of Uniprot, Kegg pathway, Pathwe classification system, and literature search.

\section{Statistical analysis}

Results were reported as mean \pm SEM. The repeatedmeasures ANOVA was used for the analysis of the escape latency, swimming distance and speed among different groups. Bonferroni's multiple comparison tests, one-way ANOVA followed by a correlation coefficient calculation were used for statistical analysis of probe times, blood manganese and AChE and ChAT activity. A $p$ value less than 0.05 is considered as statistically significant.

\section{Results}

The effect of taurine in manganese-induced memory and learning impairment

To test the effects of taurine in manganese-induced memory and spatial learning impairments, we performed the Morris Water Maze test. The acquisition trial of the MWM task is used to assess learning capacity, which is composed of the escape latency (time required to reach the platform) and the swimming distance to the platform. The probe trial is a method to measure the memory ability, which can be evaluated by the time spent in different areas of the pool or the number of target area crossings. A repeated-measure ANOVA revealed a significant difference in the escape latency $(\mathrm{F}(2,15)=9.8$, $p<0.05$, Figure $1 \mathrm{~A})$ and swimming speed $(\mathrm{F}(2,15)=16.8$, $\mathrm{p}<0.01$, Figure $1 \mathrm{~B})$ but not the swimming distance $(\mathrm{F}(2,15)=2.31, p>0.05$, Figure $1 \mathrm{C})$ among the control, manganese and taurine plus manganese groups. The mean escape latency over a period of 7 days for the control group $(31.3 \pm 3.2 \mathrm{~s})$ and taurine plus manganese group $(30.1 \pm 3.2 \mathrm{~s})$ were significantly shorter than that of the manganese alone group (48.0 $\pm 3.2 \mathrm{~s})$ (Adjustment multiple comparisons: Bonferroni, $p<0.01)$. The mean swimming speed of the control group $(11.9 \pm 0.3 \mathrm{~mm} / \mathrm{s})$ and taurine plus manganese group $(12.2 \pm 0.3 \mathrm{~mm} / \mathrm{s})$ was significantly faster than the manganese alone group $(10.0 \pm$ $0.3 \mathrm{~mm} / \mathrm{s}$ ) (multiple comparisons: Bonferroni, $p<0.05$ ). In the probe trial on day 8 , statistical analysis of the annulus crossings above the original platform position showed a significant improvement in the taurine plus manganese group compared to the manganese alone group $(\mathrm{F}(2,15)=$ $4.3, p<0.05)$. Post hoc analysis indicated that the probe trial in the control and the taurine plus manganese group has an increase in the annulus crossings compared to that of the manganese alone group (control $=7.5 \pm 1.8$; taurine + manganese $=6.5 \pm 1.5$; manganese $=2.0 \pm 0.9$; least significant difference test, $p<0.05$, Figure 1D).

\section{The effect of taurine on the blood level of manganese}

To test if the protective role of taurine in manganeseinduced neurotoxicity is achieved by reducing the level of manganese in blood, we measured the blood manganese level by the Atomic Emission Spectroscopy. After 8 weeks of treatments, the blood manganese level was significantly higher in the manganese-administrated group than that in the control group $(p=0.000)$. However, the addition of taurine failed to reduce the blood manganese level, suggesting that taurine attenuates manganese-induced toxicity without affecting the level of manganese in blood (Figure 2A).

\section{The effect of manganese and taurine on the activity of acetylcholinesterase and choline acetyltransferase} The neurotransmitter acetylcholine has been long associated with the learning and memory in past studies. 


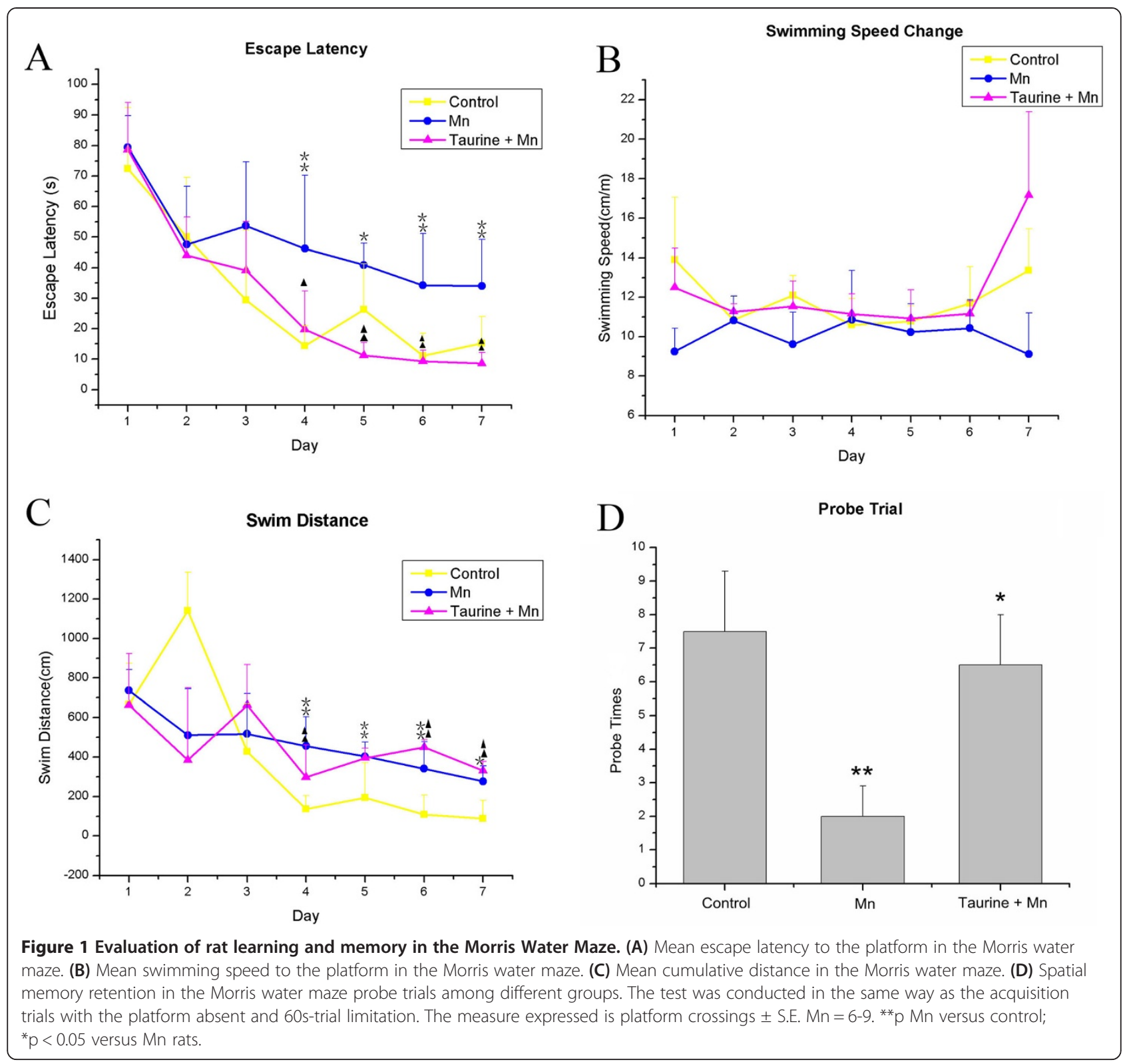

Because the level of acetylcholine is delicately regulated by the balance between the acetylcholinesterase (AChE)mediated ACh degradation and the choline acetyltransferase (ChAT)-mediated ACh synthesis, we decided to measure the activity of both enzymes. The activity of AChE in manganese group $(0.40 \pm 0.26 \mathrm{U} / \mathrm{mg})$ was not significantly different from that in the control group $(0.29 \pm 0.10 \mathrm{U} / \mathrm{mg})$. However, the combined taurine and manganese treatment significantly reduced the activity of AChE $(0.20 \pm 0.04 \mathrm{IU} / \mathrm{mg})$ compared to the manganese alone treatment $(p=0.032)$. The activity of ChAT was dramatically decreased after manganese treatment $($ control $=30.27 \pm 9.47 \mathrm{IU} / \mathrm{g} ; \mathrm{Mn}=$ $13.24 \pm 5.09 \mathrm{IU} / \mathrm{g}, p=0.001$ ). Administration of taurine $(20.88 \pm 9.50 \mathrm{IU} / \mathrm{g})$ restored ChAT activity to $79 \%$ of control (Figure 2B).
Proteomic analysis of the differences between the taurine and manganese treated rat hippocampus

We observed a total of 849 pairs of protein spots and 12 protein spots alteration when comparing the 2-D gels between the control and the manganese-treated samples (Figure 3A Mn). The identity of the 7 alterative spots were then revealed by mass spectrometry (L-lactate dehydrogenase B chain, mu-crystallin homolog, peroxiredoxin-6, actin-related protein 3 homolog, calreticulin precursor, secernin-1, dynactin subunit 3 isoform B). In addition, 785 pairs of protein spots were matched between the manganese-treated rat hippocampus and the manganese plus taurine treated rat hippocampus, while 2 alterative protein spots were successfully identified (prepro-A-type allatostatin $(\mathrm{N})$ and glial fibrillary acidic protein delta, 


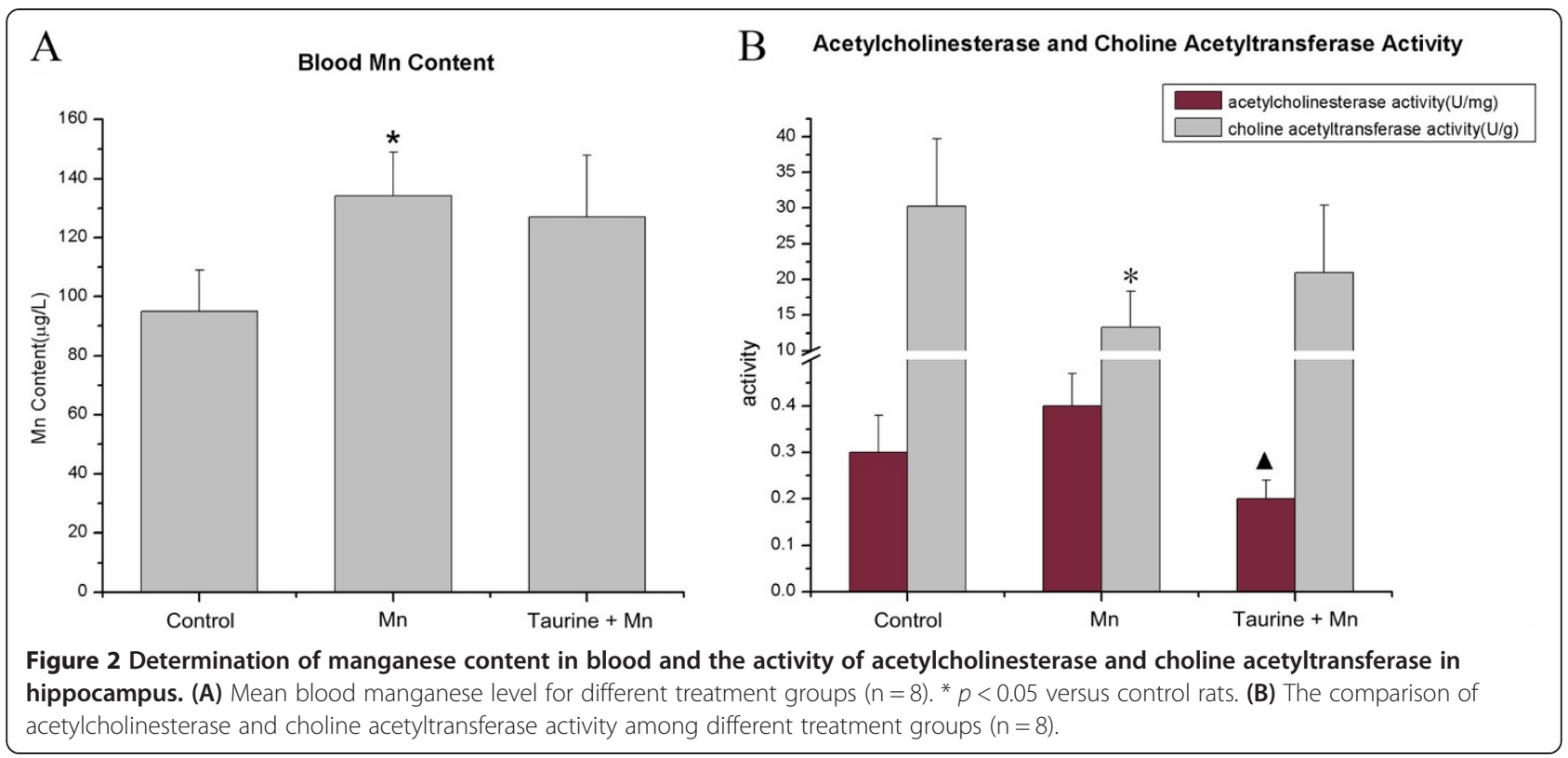

Figure 3A Taurine $+\mathrm{Mn}$ ). The detail information of all proteins identified in this study was listed in Table 1.

\section{Discussion}

Taurine has also been shown to have neuroprotective effects in many pathological conditions such as Alzheimer's and Huntington's diseases [13,14]. However, the role of taurine in manganese-induced neurotoxicity has not been reported. Research has showed that accumulation of manganese in the brain disturbed the homeostasis of taurine by significantly increasing taurine uptake in rat astrocytes, suggesting a potential benefit of taurine in manganese overload [15]. In our study, Administration of $200 \mathrm{mg} / \mathrm{kg} / \mathrm{d}$ of taurine significantly increased the ability of rats in the Morris Water Maze test. These results provided evidences to support the protective role of taurine in manganeseinduced spatial learning impairment.

Previous research has shown that taurine formed less stable metal complexes with transition metals, such as $\mathrm{Cu}^{2+}, \mathrm{Co}^{2+}, \mathrm{Cd}^{2+}, \mathrm{Fe}^{2+}, \mathrm{Mn}^{2+}$, and $\mathrm{Mg}^{2+}$ than other amino acids [16]. In this study, we also examined whether taurine is able to chelate manganese from blood. Our result indicated that taurine had no effect on the blood manganese level, which is consistent to previous reports that taurine can't remove lead from blood, kidney, liver and brain [17]. This results suggested that taurine reduces manganeseinduced neurotoxicity without affecting the level of manganese in blood.

Taurine functions as a neuromodulator to attenuate glutamate-induced neurotoxicity in the central nervous system $[18,19]$. Numerous evidences have demonstrated that acetylcholine is strongly linked to the normal function of learning and memory $[20,21]$. The effects of manganese on the activity of $\mathrm{AChE}$ and $\mathrm{ChAT}$, which are important indicators for the regulation of acetylcholine level in the brain, have been inconsistent [22-26]. We found that the manganese-induced increase in acetylcholine esterase activity and decrease in choline acetyltransferase activity were restored by taurine treatment, which is consistent with previous studies [27]. Muramatsu and his coworkers reported that taurine stabilized excitable membrane and suppressed the release of acetylcholine and norepinephrine at synapses [28]. In addition, the level of taurine is decreased in the brain of Alzheimer's patients. Moreover, taurine supplement increased acetylcholine level in the experimental animal brain [29]. In a study by Hayate and his colleagues, taurine has been shown to restore the learning and memory deficits induced by intracerebroventricularly injection of streptozotocin by increasing the expression of ChAT in hippocampus [25]. All these evidences support that taurine improves the learning and memory function by controlling the level of acetylcholine.

In the proteomic analysis, we identified 9 differentially expressed proteins between the control, manganese, and taurine plus manganese groups. Among them, dynactin participates in the development of Huntington's disease, which is an autosomal dominant neurodegenerative disorder that affects primarily the striatum and cerebral cortex. The function of prepro-A-type allatostatin $(\mathrm{N})$ is not clear yet. The rest of seven proteins all locate in cytoplasm and involve in the energy metabolism and oxidative stress pathways, implying that taurine serves as an antioxidant to protect the oxidative damages induced by manganese. Several lines of evidences have shown that taurine supplement protects oxidative damages induced by toxic compounds such as ethanol [25], lead [26] and $\beta$-amyloid [27]. 


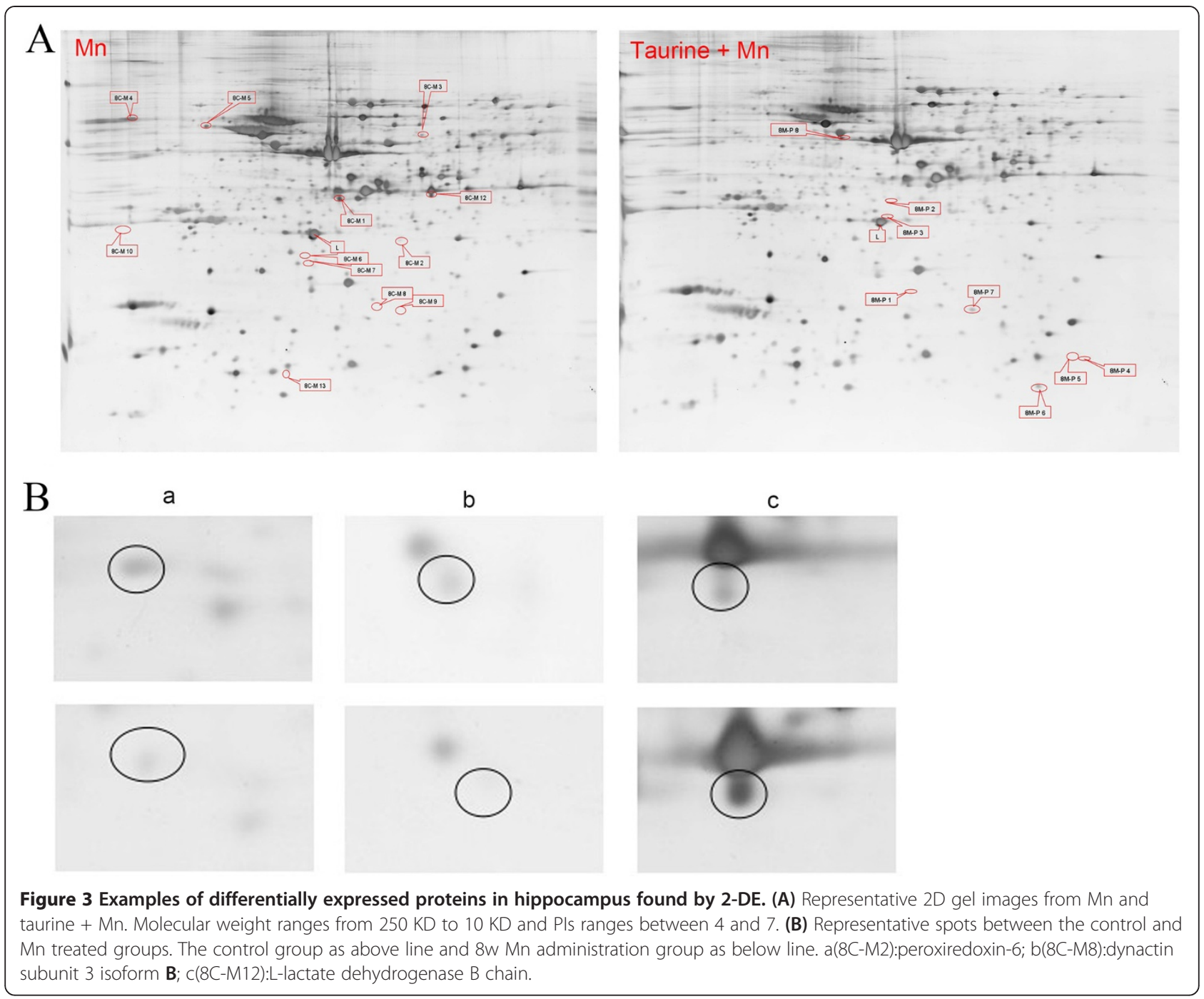

Additionally, taurine is known to prevent oxidative stress by improving electron transport chain activity which is also responsible for ATP synthesis [28]. Mg competes with $\mathrm{Mn}$ to form MgATP, which serves as a substrate for ATPase in the synthesis of ATP [29]. Therefore, it is possible that taurine facilitates MgATP formation in the presence of Mn. Glial fibrillary acidic protein (GFAP) is a classic astrocyte marker and up-regulated upon exposure of many toxicants. Here, we observed that the expression of GFAP increased in taurine plus manganese group

Table 19 identified viariation spots among different groups

\begin{tabular}{|c|c|c|c|c|c|}
\hline Spot no. & Protein identified & Accession no. & $\operatorname{Mr}(\mathrm{Da})$ & Protein PI & Protein score C.I.\% \\
\hline $8 \mathrm{C}-\mathrm{M} 1$ & Mu-crystallin homolog & gi|16758840 & 33533.1 & 5.34 & 100 \\
\hline $8 \mathrm{C}-\mathrm{M} 2$ & Peroxiredoxin-6 & gi|16758348 & 24803 & 5.64 & 98.70 \\
\hline $8 C-M 3$ & Actin-related protein 3 homolog & gi|161728791 & 47195.9 & 5.61 & 100 \\
\hline $8 \mathrm{C}-\mathrm{M} 4$ & Calreticulin precursor & gi|11693172 & 47965.8 & 4.33 & 100 \\
\hline $8 C-M 5$ & Secernin-1 & gi|68163565 & 46366.6 & 4.73 & 100 \\
\hline 8C-M 8 & Dynactin subunit 3 isoform $B$ & gi|227116275 & 17970.8 & 6.18 & 98.73 \\
\hline 8C-M 12 & L-lactate dehydrogenase B chain & gi|6981146 & 36589.1 & 5.71 & 100.00 \\
\hline $8 \mathrm{M}-\mathrm{P} 4$ & Prepro-A-type allatostatin(N) & gi|152125945 & 15419.8 & 9.77 & 98.57 \\
\hline $8 M-P 8$ & Glial fibrillary acidic protein delta & gi|5030428 & 48752.2 & 5.72 & 100 \\
\hline
\end{tabular}


compared to the manganese alone group. However, some studies have indicated that taurine treatment was associated with a reduced level of GFAP in rats after 3nitropropionic acid exposure in the xenotransplantated neurons derived from the human teratocarcinoma cell line [30]. This discrepancy could be resulted from the difference in the length of taurine treatment. Previous studies have shown that the expression of GFAP changes in a relatively slow rate $[31,32]$. Hence, it may take a longer treatment period before the expression of GFAP to decrease. The differentially expressed proteins we identified in this study still need to be further validated to elaborate their roles in the protective effects of taurine on cognitive deficit.

\section{Conclusions}

In summary, taurine restores the activity of AChT and ChAT, which are critical for the regulation of acetylcholine. We have identified seven differentially expressed proteins specifically induced by manganese and two proteins induced by taurine from the rat hippocampus. Our results support that taurine improves the impaired learning and memory ability caused by excessive exposure of manganese.

\section{Competing interests}

The authors declare that they have no competing interests.

\section{Authors' contributions}

CLL, ST, ZJM and LYS carried out the experimental work. CLL, SCG and XYL designed the study, coordinated the experiments, analyzed data and wrote the manuscript. YYH and YPL conducted the statistical analyses. NM coordinated the experiments and manuscript modification. All authors read and approved the final manuscript.

\section{Acknowledgements}

The authors thank the institute of life science and technology of the University of Guangxi for mass spectrometry technical assistance and Ying $\mathrm{Xu}$ for data analysis and illustration assistance. This work was supported by the Chinese National Natural Science Foundation NO30660156.

\section{Author details}

'Department of Food and Nutrition, School of Public Health, Guangxi Medical University, 22 Shuangyong Road, 530021 Nanning, Guangxi, P.R China. ${ }^{2}$ Department of Immunology, School of Preclinical medicine, Guangxi Medical University, 22 Shuangyong Road, 530021 Nanning, Guangxi, P.R. China. ${ }^{3}$ China Tobacco GuangXi Industrial CO. LTD, Nanning, China. ${ }^{4}$ Mie University, Faculty of Medicine, Suzuka, Mie 510-0293, Japan.

Received: 15 February 2014 Accepted: 18 May 2014

Published: 24 May 2014

\section{References}

1. Josephs KA, Ahlskog JE, Klos KJ, Kumar N, Fealey RD, Trenerry MR, Cowl CT: Neurologic manifestations in welders with pallidal MRI T1 hyperintensity. Neurology 2005, 64(12):2033-2039.

2. Klos KJ, Chandler M, Kumar N, Ahlskog JE, Josephs KA: Neuropsychological profiles of manganese neurotoxicity. Eur J Neurol 2006, 13(10):1139-1141.

3. Mergler D, Huel G, Bowler R, Iregren A, Belanger S, Baldwin M, Tardif R, Smargiassi A, Martin L: Nervous system dysfunction among workers with long-term exposure to manganese. Environ Res 1994, 64(2):151-180.

4. Koller WC, Lyons KE, Truly W: Effect of levodopa treatment for parkinsonism in welders A double-blind study. Neurology 2004, 62(5):730-733.
5. Crossgrove J, Zheng W: Manganese toxicity upon overexposure. NMR Biomed 2004, 17(8):544-553.

6. Herrero Hernandez E, Discalzi G, Valentini C, Venturi F, Chio A, Carmellino C, Rossi L, Sacchetti A, Pira E: Follow-up of patients affected by manganese-induced Parkinsonism after treatment with CaNa2EDTA. Neurotoxicology 2006, 27(3):333-339.

7. Leon R, Wu H, Jin Y, Wei J, Buddhala C, Prentice H, Wu JY: Protective function of taurine in glutamate-induced apoptosis in cultured neurons. J Neurosci Res 2009, 87(5):1185-1194.

8. Lu X-Y, Shivaraj MC, Marcy G, Low G, Ryu JR, Zhao X, Rosales FJ, Goh ELK: Taurine Induces Proliferation of Neural Stem Cells and Synapse Development in the Developing Mouse Brain. PLOS ONE 2012, 7(8):e42935.

9. Gurer $H$, Ozgunes $H$, Saygin $E$, Ercal N: Antioxidant effect of taurine against lead-induced oxidative stress. Arch Environ Contam Toxicol 2001, 41(4):397-402

10. Hwang $D$, Wang $L$ : Effect of taurine on toxicity of cadmium in rats. Toxicology 2001, 167(3):173-180.

11. Manna P, Sinha M, Sil PC: Taurine plays a beneficial role against cadmium-induced oxidative renal dysfunction. Amino Acids 2009, 36(3):417-428

12. Alban A, David SO, Bjorkesten L, Andersson C, Sloge E, Lewis S, Currie I: A novel experimental design for comparative two-dimensional gel analysis: two-dimensional difference gel electrophoresis incorporating a pooled internal standard. Proteomics 2003, 3(1):36-44.

13. Louzada PR, Paula Lima AC, Mendonca-Silva DL, Noel F, De Mello FG, Ferreira ST: Taurine prevents the neurotoxicity of $\beta$-amyloid and glutamate receptor agonists: activation of GABA receptors and possible implications for Alzheimer's disease and other neurological disorders. FASEB J 2004, 18(3):511-518.

14. Tadros MG, Khalifa AE, Abdel-Naim AB, Arafa HM: Neuroprotective effect of taurine in 3-nitropropionic acid-induced experimental animal model of Huntington's disease phenotype. Pharmacol Biochem Behav 2005. 82(3):574-582

15. Fordahl SC, Anderson JG, Cooney PT, Weaver TL, Colyer CL, Erikson KM: Manganese exposure inhibits the clearance of extracellular GABA and influences taurine homeostasis in the striatum of developing rats. Neurotoxicology 2010, 31(6):639-646.

16. Wright CE, Tallan HH, Lin YY: Taurine: biological update. Annu Rev Biochem 1986, 55(1):427-453.

17. Flora SJ, Pande M, Bhadauria S, Kannan G: Combined administration of taurine and meso 2, 3-dimercaptosuccinic acid in the treatment of chronic lead intoxication in rats. Hum Exp Toxicol 2004, 23(4):157-166.

18. Muramatsu M, Kakita K, Nakagawa K, Kuriyama K: A modulating role of taurine on release of acetylcholine and norepinephrine from neuronal tissues. Jpn J Pharmacol 1978, 28(2):259-268.

19. Birdsall TC: Therapeutic applications of taurine. Altern Med Rev 1998, 3(2):128-136.

20. Martyn AC, De Jaeger X, Magalhaes AC, Kesarwani R, Goncalves DF, Raulic S, Guzman MS, Jackson MF, Izquierdo I, MacDonald JF: Elimination of the vesicular acetylcholine transporter in the forebrain causes hyperactivity and deficits in spatial memory and long-term potentiation. Proc Natl Acad Sci 2012, 109(43):17651-17656.

21. Croxson PL, Browning PG, Gaffan D, Baxter MG: Acetylcholine Facilitates Recovery of Episodic Memory after Brain Damage. J Neurosci 2012, 32(40):13787-13795

22. Javed H, Khan A, Vaibhav K, Moshahid Khan M, Ahmad A, Ejaz Ahmad M Ahmad A, Tabassum R, Islam F, Safhi MM, Islam F: Taurine ameliorates neurobehavioral, neurochemical and immunohistochemical changes in sporadic dementia of Alzheimer's type (SDAT) caused by intracerebroventricular streptozotocin in rats. Neuro/ Sci 2013, 34(12):2181-2192.

23. Lai JC, Leung TK, Lim L: Brain regional distribution of glutamic acid decarboxylase, choline acetyltransferase, and acetylcholinesterase in the rat: effects of chronic manganese chloride administration after two years. J Neurochem 1981, 36(4):1443-1448

24. Christina E, Joachim T, Silvia K, Ulrich S, Konrad LÈ, Hermona S, Jochen K: Compensatory mechanisms enhance hippocampal acetylcholine release in transgenic mice expressing human acetylcholinesterase. Neuropathol 2001, 77:638-646.

25. Kerai MD, Waterfield CJ, Kenyon SH, Asker DS, Timbrell JA: Reversal of ethanol-induced hepatic steatosis and lipid peroxidation by taurine: a study in rats. Alcohol Alcohol 1999, 34(4):529-541. 
26. Yu S-S, Wang M, Li X-M, Chen W-H, Chen J-T, Wang H-L, Ruan D-Y: Influences of different developmental periods of taurine supplements on synaptic plasticity in hippocampal CA1 area of rats following prenatal and perinatal lead exposure. BMC Dev Biol 2007, 7(1):51.

27. Saransaari P, Oja SS: taurine and neural cell damage. Amino Acids 2000, 19(3-4):509-526

28. Jong CJ, Azuma J, Schaffer S: Mechanism underlying the antioxidant activity of taurine: prevention of mitochondrial oxidant production. Amino Acids 2012, 42(6):2223-2232.

29. Hermans C, Conn SJ, Chen J, Xiao Q, Verbruggen N: An update on magnesium homeostasis mechanisms in plants. Metallomics 2013, 5(9):1170-1183.

30. Sakurai T, Miki T, Li HP, Miyatake A, Satriotomo I, Takeuchi Y: Colocalization of taurine and glial fibrillary acidic protein immunoreactivity in mouse hippocampus induced by short-term ethanol exposure. Brain Res 2003, 959(1):160-164.

31. Lieth E, Barber AJ, Xu B, Dice C, Ratz MJ, Tanase D, Strother JM: Glial reactivity and impaired glutamate metabolism in short-term experimental diabetic retinopathy. Penn State Retina Res Group Diabetes 1998, 47(5):815-820.

32. Li Q, Zemel E, Miller B, Perlman I: Early retinal damage in experimental diabetes: electroretinographical and morphological observations. Exp Eye Res 2002, 74(5):615-625.

doi:10.1186/1423-0127-21-51

Cite this article as: Lu et al.: Taurine improves the spatial learning and memory ability impaired by sub-chronic manganese exposure. Journal of Biomedical Science 2014 21:51.

\section{Submit your next manuscript to BioMed Central and take full advantage of:}

- Convenient online submission

- Thorough peer review

- No space constraints or color figure charges

- Immediate publication on acceptance

- Inclusion in PubMed, CAS, Scopus and Google Scholar

- Research which is freely available for redistribution 